\begin{tabular}{|c|c|c|}
\hline & JHE 5 (2) (2020) 61-65 & $m 1 \mid=$ \\
\hline & Journal of Health Education & \\
\hline $\begin{array}{l}\text { Journal of } \\
\text { Healtheducation } \\
\text { nats }\end{array}$ & http://journal.unnes.ac.id/sju/index.php/jhealthedu & 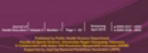 \\
\hline
\end{tabular}

\title{
Husband's Permission as A Determinant for Breast Cancer Screening among Women of Childbearing Age
}

\section{Oluwatobi Daniel Nofiu}

DOI: http://dx.doi.org/10.15294/jhe.v5i2.38565

University of Maiduguri Borno State, Nigeria

\section{History Article}

Submitted 3 May 2020

Revised 9 August 2020

Accepted 27 September 2020

\section{Keywords}

breast cancer screening; determinant; husband's permission; southwest zone Nigeria; women of childbearing age

\begin{abstract}
Background: Breast screening reduces breast cancer-associated morbidity and mortality, a means to early detection, also increases the chances for successful treatment and cure of the disease. This study was conducted to assess the husband's permission as a determinant of breast cancer screening among women of childbearing age in The Southwest zone, Nigeria.

Method: Ex-post facto research design was used for this paper. A total sample of 768 women of childbearing age in The Southwest zone, Nigeria from a population of $8,261,284$ were selected through multi-stage sampling procedures of simple random sampling, proportionate, and systematic sampling techniques. Out of the 768 copies of the questionnaire distributed, 762 were valid for analyses. Inferential statistics of a one-sample t-test was used to test the data collected at 0.05 level of significance.

Results: The results revealed that husband's permission is a determinant of breast cancer screening among women of childbearing age was significant with a t-value of 4.921 and a p-value of 0.001 at 0.05 level of significance.

Conclusion: It was concluded that the husband's permission was a determinant of breast cancer screening among women of childbearing age in The Southwest zone, Nigeria. Based on the conclusion, it was recommended that husbands should be encouraged and enlightening on breast cancer and its screening in other to allow their wives to go for screening by governmental and non-governmental organizations through mass media, community, and town campaign of breast cancer screening.
\end{abstract}

\section{How to Cite}

Nofiu, O. D. (2020). Husband's Permission as A Determinant for Breast Cancer Screening among Women of Childbearing Age. JHE (Journal of Health Education), $5(2), 61-65$.

\footnotetext{
Corresponding Author:

Bama Road, Maiduguri, Borno State, Nigeria

E-mail: danie14gem@gmail.com
} 


\section{INTRODUCTION}

Breast cancer is a common cause of cancer-related deaths in most developing countries. Breast cancer is the most frequently diagnosed neoplastic disease in women around menopause often leading to a significant reduction of these women's ability to function normally in everyday life (Kamińska, et al., 2015). Breast cancer is the type of cancer that develops from breast tissue; it is mostly common in women and it is one of the most studied diseases, largely because of its high mortality (second to lung cancer) (Oguntunde, et al., 2017). Breast cancer is a metastatic cancer and can commonly transfer to distant organs such as the bone, liver, lung and brain, which mainly accounts for its incurability (Sun, et al., 2017).

Female breast cancer is a major global public health problem with an estimated 1,384,155 new cases worldwide and over 459,000 related deaths annually (Adebimpe, et al., 2018). Studies have shown a steady increase in the incidence of breast cancer in Nigeria from 15.3 per 100,000 in 1976 to 33.6 per 100,000 in 2015 to 52.1 per 100,000 in 2012 (World Health Organization, 2016). The incidence of breast cancer is increasing in the developing world due to increased life expectancy, increased urbanization and adoption of western lifestyle (World Health Organization, 2013). Various factors also affect the incidence of breast cancer, of which genetic factors, environmental factors, and lifestyle are the most important ones, and also many factors such as parities, lactation, and exercise play important roles in reducing the risk of this disease (Momenimovahed \& Salehiniya, 2019).

Breast cancer causes are unknown; thus it is considered as a disease primarily associated with some risk factors. Multiple risk factors for breast cancer are well-established; these include breast density, reproductive (parity and age at first birth), menstrual (menopausal status and age at menarche), and modifiable lifestyle factors such as body mass index (BMI), hormone replacement therapy (HRT) use and alcohol consumption (Ho et al. 2020). These factors are simply being a female, getting older, family history of breast cancer especially a first-degree relative, early menarche at the age of 12 and under, late menopause after the age of 55 years, and having the first child after the age of 30 years.

Previous studies have reported that there are several common factors present in women diagnosed with breast cancer, such as their ages, ages at menarche and menopause, family histories, lifestyles and oral contraceptive usage (A1- solami et al. 2019). Research from Tabrizi (2018) found significant relationships among these factors with breast cancer such as income, menopause status, a history of breast cancer in close relatives, beliefs, inaccessibility, knowledge, cues to action, emotions, self-care, and life priorities $(\mathrm{P}<0.05)$ (Tabrizi, et al., 2018). Breast-feeding appears to be protective against breast cancer, and null parity is associated with an increased risk of developing breast cancer. Prolonged use of oral contraceptive pills, hormonal therapy, and being overweight or obese have been found to increase breast cancer risk among menopausal women (Jago, et al., 2014).

Breast screening reduces breast cancer associated morbidity and mortality, a means to early detection, also increases the chances for successful treatment and cure of the disease (Chor, et al., 2014), but also improves chances of survival and lessens the need of invasive treatment. Ensuring availability of early diagnostic and screening services and taking immediate steps have been regarded as the two main strategies for warranting improvement in the prognostic outcome (Abulkhair, et al., 2010). The assumption is that early detection will improve outcomes. A number of screening tests have been employed, including clinical and self-breast exams, mammography, genetic screening, ultrasound, and magnetic resonance imaging.

Determinants are threat to women's health and well-being, and health indicators in Nigeria are unfavorable to mothers. No matter how equipped a health facility is, it is the level of patronage that makes the difference to good health of both mother and child. Thomas et al. (2012) noted that role of husbands in encouraging or obstructing women's access to screening may be an important issue in traditional. Men allow their women to go for breast screening while some reported otherwise (Kinnon, 2018). Other men indicated that they are not comfortable, especially if the test is being performed by a male health care worker. Additionally, Estrada, et al. (2014) noted that husband's permission contribute to underuse of breast cancer screening methods among women.

The researcher gathered information that women with symptoms of late stage of breast cancer disease, such as a breast reddish, swollen, tender breast, but refusing to go to the clinic/hospital. From consultation with women, many of them did not want to go for check-up because of their husband's. Some thought it was a mere infection of the breast that could be easily cured with drugs. These generated a lot of questions as to whether these women are aware about the health 
consequences of not attending clinics/ hospitals for breast cancer screening. There were different screening of early diagnosis of breast cancer such as Breast Self-Examination, physical examination by a medical doctor and mammography. This has therefore, prompted the researcher to assess whether husband's permission is a determinant of breast cancer screening among women of childbearing age in The Southwest zone, Nigeria

\section{METHODS}

The research design adopted for this study was ex post facto research design. The sample size of this study was 768 women of childbearing age between the ages of $18-49$ years as suggested that in a population of 1,000,000 and above, a sample size of 384 can be used in a study (Research Advisor 2006). However, the researcher doubled the figure to have a wider coverage of respondents for the purpose of generalization of findings to the target population. A multi-stage sampling technique that involves a simple random sampling, proportionate sampling and systematic sampling techniques was used for this study. The first stage involved the use of simple random sampling technique to select five (5) states from six (6) existing states which are Ekiti, Lagos, Ondo, Osun and Oyo by writing all the name of States on a pieces of paper, folded and dropped in a container, shuffled it, and the selection was made in order to get equal chance of selection.

The instrument that was used in collecting data for this research was a researchers' structured questionnaire. In order to establish the face and content validity of the instrument, the questionnaire was vetted by five (5) jurors from Departments of Human Kinetics and Health Education and Nursing Sciences, Ahmadu Bello University, Zaria. The comments, observations, corrections and suggestions were incorporated and a final draft of the questionnaire was prepared and used for pilot study. Descriptive statistics of means and standard deviation was used to answer the research questions, thus, any response that has a mean aggregate of 2.5 and above was accepted as positive and any response that has a mean score of less than 2.5 was negative or not accepted. One sample t-test was used to test the formulated hypotheses at 0.05 alpha level of significance

\section{RESULTS AND DISCUSSIONS}

Table 1 reveals the mean and standard deviation on the responses of the respondents whether husband's permission determine breast cancer screening among women of childbearing age. My husband did not allow me because health care center is far from where I live has a mean of 3.7894 and standard deviation of 1.5796 , my husband did not allow me to go for breast checkup has mean of 3.2134 and standard deviation of 1.3013, my husband did not allow me because of the personnel in the hospital are not friendly has a mean of 3.6815 and 1.5362 while my husband did not allow me because of the Fear of breast cancer has a mean of 3.5103 and standard deviation of 1.3109. It was revealed that the aggregate mean 3.5131 is greater than 2.5 constant mean. Therefore, husband's permission determines breast cancer screening among women of childbearing age in The Southwest zone, Nigeria.

Table 1. Mean scores of responses on the husband's permission and breast cancer screening among women of childbearing age

\begin{tabular}{lll}
\hline Item & Mean & $\begin{array}{l}\text { Standard } \\
\text { Devia- } \\
\text { tion }\end{array}$ \\
\hline
\end{tabular}

My husband did not allow

me because health care

center is far from where

$3.7894 \quad 1.57957$

I live

My husband did not allow

me to go for breast check $\quad 3.2134 \quad 1.30132$

up

My husband did not allow me because of the personnel in the hospital are not $3.6815 \quad 1.53618$ friendly.

My husband did not allow me because of my age

$3.3707 \quad 1.47334$

My husband did not allow me because of the fear of $\quad 3.5103 \quad 1.31097$ breast cancer.

\begin{tabular}{lll} 
Aggregate Mean & 3.5131 & 1.44028 \\
\hline
\end{tabular}

Table 2 reveals that husband's permission is a determinant of breast cancer screening among women of childbearing age. This is because the one-sample t-test calculated value is 4.921 greater than the t-critical is 1.972 at degree of freedom 761 with probability value 0.001 is less than 0.05 level of significance. Thus, this result shows that the sub-hypothesis (null) which states that "Husband's permission among women of childbearing age in The Southwest zone, Nigeria is not significant determinant for breast cancer screening" is therefore rejected.

Studies of African American and others 
have found positive associations between subjective perceptions of support for breast and cervical cancer screening (eg, having friends or family who encouraged screening) and actual cancer screening behaviors (Mouttapa et al., 2016). The perceived receipt of social support is believed to be a motivator for multiethnic women to get routine cancer screenings. Mouttapa (2016) findings of a relationship between PI women perceived social support and Pap testing behaviors are consistent with their prediction and the suggestion that enhancing the quality of women's social networks, specifically their relationship with their husband/ male partner, may facilitate cancer screening efforts above and beyond the impact of traditional cancer prevention strategies (eg, increasing knowledge of cancer risk factors).

In the Middle East, socio-cultural factors influence women's view of breast cancer screening. For example, in Saudi Arabia, men directly influence women's decision making with regard to healthcare services and their own perceptions of self-care (Al-Dasoqi et al., 2017). Arab men perceive that their opinions and support are a major factor influencing female family members' participation in breast cancer screening, it is important that any program instituted to increase such screening participation be aimed at both men and women (Donnelly et al., 2017).

As with many countries in the world, Arabs in Qatar characteristically are adherent to patriarchal customs and traditions (Donnelly et al., 2017). Nevertheless, the fear that a woman's breasts may be exposed and palpitated by a male health care professional can be a contributing factor in the reluctance of women to participate in such screening activities or in getting their husbands' or fathers' approval for breast examinations (Donnelly et al., 2017).

Breast cancer may have direct consequences on the husband. For instance, distress was found to be distributed among husbands of the women diagnosed with breast cancer, even though it was not as much of the patients' distress themselves (Yusoff, et al., 2012). However, some studies reported that spouses (regardless of gender) had more distress than patients (Yusoff et al., 2012).

The result also revealed that husband's permission is a determinants of breast cancer screening among women of childbearing age with $t$ value of 4.921 and $p$-value $0.001<0.05$. This means that the husband's permission is one of the determinants of breast cancer screening among women of childbearing age. The finding of this study is in line with the study of Thomas et al.
(2012) that role of husbands in encouraging or obstructing women's access to screening may be an important issue in traditional societies (Thomas, et al., 2012). In this survey, only $4 \%$ of women reported that their husbands ever opposed their desire to screen, while $>2 / 3$ rd of husbands were clearly supportive. Husband's positive support as well as educational level were determinants of women's participation in breast cancer screening activities. In results, women who perceived a positive spousal attitude (versus a neutral one) were significantly more likely to ever-obtain a mammography. Spousal support was the only variable which appeared to affect regular adherence to yearly mammography. Recognizing the importance of support from spouses, that men to encourage women for screening. Most men appreciated the importance of regular breast cancer screening in promoting women's health and in early detection of breast cancer. They felt they had an important role in encouraging the women in their lives to participate in breast cancer screening activities, but were adamant that any examination must be performed by a female health care professional (Donnelly et al., 2017).

Table 2. One sample t test on husband's permission as a determinant of breast cancer screening among women of childbearing age

\begin{tabular}{llllll}
\hline & Mean & $\begin{array}{l}\text { Std. De- } \\
\text { viation }\end{array}$ & $\begin{array}{l}\mathrm{t}- \\
\text { value }\end{array}$ & df & $\begin{array}{l}\mathrm{P}- \\
\text { value }\end{array}$ \\
\hline $\begin{array}{l}\text { Ag- } \\
\text { gregate } \\
\text { mean }\end{array}$ & 3.51 & 1.44 & 4.92 & 761 & \\
$\begin{array}{l}\text { Con- } \\
\text { stant } \\
\text { mean }\end{array}$ & 2.50 & 0.001 & & & \\
\hline $\mathrm{t}(761)=1.972, \mathrm{P}<0.05$ & & & & 0.001 \\
\end{tabular}

Kinnon (2018) revealed that some men allow their women to go for breast screening while some reported otherwise. Other men indicated that they are not comfortable, especially if the test is being performed by a male health care worker. Men believed that breast cancer preventive practices must be performed in a similar context of women's religious and cultural background (A1Dasoqi et al., 2017). Hence, there is an urgent need to pay more attention to spreading awareness among men, as they are associates, and they need to be armed with proper awareness (Adebimpe et al., 2018). It is being agreed that breast cancer is a disease that presents spouses with the new environment of life, mostly in relation to the marital satisfaction, communication and inter- 
personal support (Yusoff et al., 2012). Furthermore, husbands' breast cancer knowledge plays a significant role in wives' attitudes and practices related to breast cancer (Adebimpe et al., 2018).

\section{CONCLUSION}

From the results and findings of this paper, it was concluded that husband's permission was a determinant of breast cancer screening among women of childbearing age in The Southwest zone, Nigeria. It was therefore recommended that husbands should be encourage and enlightening on breast cancer in other to allow their wives to go for screening by governmental and non-governmental organizations through community and town campaign of the importance of breast cancer screening. Besides, governmental and non-governmental organizations should put more effort in making breast cancer screening free consultation in town and communities.

\section{REFERENCES}

Abulkhair, O. A., Al Tahan, F. M., Young, S. E., Musaad, S. M., \& Jazieh, A. R. M. (2010). The first national public breast cancer screening program in Saudi Arabia. Annals of Saudi medicine, 30(5), 350-357.

Olalekan, A. W., Oluwaseun, F. A., \& Oladele, H. A. W. (2018). Prevalence and knowledge of Salmonella infections among food handlers: Implications for school health in Southwestern Nigeria. Sahel Medical Journal, 21(2), 99-103.

Alsolami, F. J., Azzeh, F. S., Ghafouri, K. J., Ghaith, M. M., Almaimani, R. A., Almasmoum, H. A., ... \& Tashtoush, S. H. (2019). Determinants of breast cancer in Saudi women from Makkah region: a case-control study (breast cancer risk factors among Saudi women). BMC public health, 19(1), 1554-15560.

Chor, J. S. Y., Lam, H. C. Y., Chan, A., Lee, H. M., Fok, E., Griffiths, S., \& Cheung, P. (2014). Socioeconomic disparity in breast cancer detection in Hong Kong-a high income city: retrospective epidemiological study using the breast cancer registry. PloS one, 9(10), e107630.

Al Dasoqi, K., Zeilani, R., Bawadi, H., \& Al Dasoqi, A. (2017). Perspectives and Attitudes of Jordanian Male College Students on Breast Cancer Screening. Journal of Cancer Education, 32(1), 24-30.

Donnelly, T. T., A1-Khater, A. H., A1-Bader, S. B., AlKuwari, M. G., Abdul Malik, M. A., Al-Meer, N., \& Singh, R. (2017). Perceptions of Arab men regarding female breast cancer screening examinations-Findings from a Middle East study. PloS one, 12(7), e0180696.

Ho, P. J., Lau, H. S. H., Ho, W. K., Wong, F. Y., Yang,
Q., Tan, K. W., ... \& Li, J. (2020). Incidence of breast cancer attributable to breast density, modifiable and non-modifiable breast cancer risk factors in Singapore. Scientific reports, 10(1), $1-11$.

Jago, R., Thompson, J. L., Sebire, S. J., Wood, L., Pool, L., Zahra, J., \& Lawlor, D. A. (2014). Crosssectional associations between the screen-time of parents and young children: differences by parent and child gender and day of the week. International Journal of Behavioral Nutrition and Physical Activity, 11(1), 54-60.

Kamińska, M., Ciszewski, T., Łopacka-Szatan, K., Miotła, P., \& Starosławska, E. (2015). Breast cancer risk factors. Przeglad menopauzalny $=$ Menopause review, 14(3), 196-202.

Kinnon, J. B. (2018). Breast cancer: The increasing threat to young black women. Women's Health Section. Ebony, 1(1), 1-7.

Momenimovahed, Z., \& Salehiniya, H. (2019). Epidemiological characteristics of and risk factors for breast cancer in the world. Breast Cancer: Targets and Therapy, 11(1), 151-64.

Mouttapa, M., Park Tanjasiri, S., Wu Weiss, J., SablanSantos, L., DeGuzman Lacsamana, J., Quitugua, L., ... \& Tupua, M. (2016). Associations between women's perception of their husbands'/partners' social support and Pap screening in Pacific Islander communities. Asia Pacific Journal of Public Health, 28(1), 61-71.

Oguntunde, P. E., Adejumo, A. O., \& Okagbue, H. I. (2017). Breast cancer patients in Nigeria: data exploration approach. Data in brief, 15(1), 47-57.

Research Advisor. (2006). Excel Compatible Sample Size Table. Retrieved March 14, 2018 (www. researchadvisor.com).

Sun, Y. S., Zhao, Z., Yang, Z. N., Xu, F., Lu, H. J., Zhu, Z. Y., ... \& Zhu, H. P. (2017). Risk factors and preventions of breast cancer. International journal of biological sciences, 13(11), 1387-1397.

Tabrizi, F. M., Vahdati, S., Khanahmadi, S., \& Barjasteh, S. (2018). Determinants of breast cancer screening by mammography in women referred to health Centers of Urmia, Iran. Asian Pacific Journal of Cancer Prevention: APJCP, 19(4), 9971003.

Thomas, D. B., Gao, D. L., Ray, R. M., Wang, W. W., Allison, C. J., Chen, F. L., ... \& Li, W. (2002). Randomized trial of breast self-examination in Shanghai: final results. Journal of the National Cancer Institute, 94(19), 1445-1457.

World Health Organization. (2013). Breast Cancer: Prevention and Control. Fact Sheet No. 297. Retrieved (http://www.who.int/mediacentrre/ factsheets/fs297).

World Health Organization. (2016). The World Health Report 1996: Fighting Disease, Fostering Development: Executive Summary. Geneva.

Yusoff, N., Reiko Yap, K. M., \& Ahmad, A. (2012). Husbands' experience with their wives' breast cancer: a qualitative study. Malaysian Journal of Public Health Medicine, 12(1), 31-38. 